\title{
Development of a Copper-electrodeposited Gold Electrode for an Amperometric Creatinine Sensor to Detect Creatinine in Urine without Pretreatment
}

\author{
Naoko SATO, Kouta TAKEDA, ${ }^{\dagger, \S}$ and Nobuhumi NAKAMURA*,§ (D) \\ Department of Biotechnology and Life Science, Tokyo University of Agriculture and Technology, Koganei, Tokyo 184-8588, Japan \\ *Corresponding author: nobu1@cc.tuat.ac.jp
}

\section{ABSTRACT}

A copper-electrodeposited gold electrode that can quantitatively detect creatinine without being affected by urine components and can use collected urine as it is produced. In this study, the effect of interfering compounds was eliminated, and the linear range was expanded by increasing the concentration of Nafion covering the electrodes. Furthermore, by extending the electrodeposition time, the linear range was further expanded, and it was possible to measure concentrations up to $12.3 \mathrm{mM}(\mathrm{M}=$ mol dm${ }^{-3}$ ), which is equivalent to the creatinine concentration range in the urine of healthy individuals.

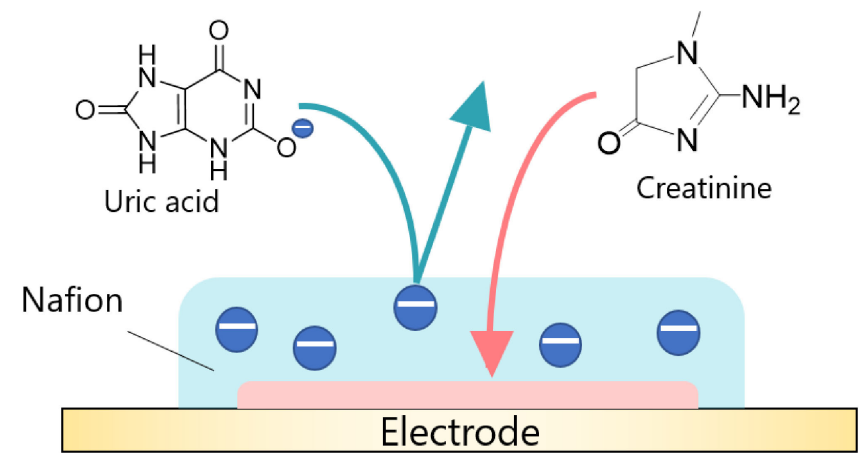

(C) The Author(s) 2021. Published by ECSJ. This is an open access article distributed under the terms of the Creative Commons Attribution 4.0 License (CC BY, http://creativecommons.org/licenses/by/4.0/), which permits unrestricted reuse of the work in any medium provided the original work is properly cited. [DOI: 10.5796/electrochemistry.21-00016].

Keywords : Creatinine Sensor, Amperometric Sensor, Point of Care, Spot Urine

\section{Introduction}

Measuring the concentration of urine components is important for the early diagnosis of illnesses and daily health care. For example, urinary sugar is a biomarker of diabetes, and uric acid is a biomarker of gout. Urine can be collected without physical and mental stress, and its sampling is noninvasive, making it a good sample for point-of-care testing. However, the concentration of urine components is affected by the amount of water in the body and urine. Therefore, when spot urine is used as a sample, it is problematic when the component concentration fluctuates greatly depending on the collection conditions. Creatinine is used as an internal standard to solve this problem because the daily urinary excretion of creatinine is primarily determined by muscle mass and is not very susceptible to physiological variables. ${ }^{1}$ The method of measuring the amount of creatinine in spot urine is important. The Jaffe method has been proposed as the most popular method for measuring the creatinine concentration. ${ }^{2}$ In the Jaffe method, creatinine picric acid, which is the reaction product of creatinine and picric acid, is quantified by spectroscopy. However, this reaction has low selectivity, and the reaction of ascorbic acid, which is one of the components in urine, is a problem, resulting in a higher value than there actually is. In addition, spectroscopic measurements are not suitable for point-of-care detection because they require expensive equipment and cumbersome operations. There have been many reports on sensors using electrochemical methods as quick and easy measurement methods. ${ }^{3,4}$ There are two main types of

'Present addresses: Institute for Molecular Science, National Institutes of Natural Sciences, Okazaki, Aichi 444-8787, Japan

${ }^{\S}$ ECSJ Active Member

N. Nakamura (D) orcid.org/0000-0002-5373-2972 electrochemical sensors: biosensors that use enzymes and nonenzymatic sensors. The mainstream biosensors are those using three enzymes, creatinine amidohydrolase, creatine amidinohydrolase, and sarcosine oxidase, and amperometric sensors have also been reported..$^{5}$ The greatest advantage of enzyme biosensors is their high substrate specificity. However, the method using these three enzymes presents a problem in that it is easily affected by electrically active components because it requires high potential. Other problems include the general instability of enzymes and the effects of creatine, which is naturally present in urine, on measurements. Nonenzymatic sensors, on the other hand, generally have the advantage of being stable and inexpensive. For example, a scheme for creatinine detection based on the formation of a soluble coppercreatinine complex on the surface of a copper electrode was reported. ${ }^{6}$ In this scheme, cuprous oxide is converted to a soluble copper-creatinine complex, which is released from the electrode surface. The copper exposed on the electrode surface is electrochemically oxidized, and the oxidation current is detected at this time. As a result, this current value reflects the concentration of creatinine in the solution. It is expected that creatinine measurement will be easier and cheaper than using this method. However, to the best of our knowledge, no sensor has been reported that covers the concentration range of creatinine contained in the collected urine. In addition, no amperometric sensor based on this scheme has been reported. In this study, we investigated the establishment of an amperometric method for creatinine detection using a copper electrodeposition electrode. Since it is intended for use in pointof-care tests on urine, it is important that urine is unaffected by other components and that relatively high concentrations of creatinine can be measured without pretreatment. The effects of the concentration of the Nafion solution applied to the electrode and the electrodeposition time of copper were investigated. 


\section{Experimental}

\subsection{Chemicals}

Copper (II) sulfate-5-hydrate $\left(\mathrm{CuSO}_{4} \cdot 5 \mathrm{H}_{2} \mathrm{O}\right)$, creatinine, and dopamine (DA) hydrochloride were purchased from Sigma-Aldrich (Tokyo, Japan). Sulfuric acid $\left(\mathrm{H}_{2} \mathrm{SO}_{4}\right)$, Nafion (20 wt\% Nafion dispersion solution DE2021CS type), sodium dihydrogen phosphate $\left(\mathrm{NaH}_{2} \mathrm{PO}_{4}\right)$, disodium hydrogen phosphate $\left(\mathrm{Na}_{2} \mathrm{HPO}_{4}\right)$, ascorbic acid (AA), and uric acid (UA) were purchased from FUJIFILM Wako Pure Chemical Corporation (Osaka, Japan). D-glucose (Glu) was purchased from Kanto Chemical Co., Inc. (Tokyo, Japan).

\subsection{Fabrication of the copper-electrodeposited gold electrode}

Rotating disk gold electrodes (RDE2 AUE $\phi 3 \mathrm{~mm}$ manufactured by BAS) were polished using an electrode polishing kit. After polishing, the electrodes were thoroughly rinsed with distilled water and sonicated for 5 minutes. The polished gold electrodes were electrochemically cleaned by scanning the potential from $-0.2 \mathrm{~V}$ to $1.5 \mathrm{~V}$ (vs. $\mathrm{Ag} / \mathrm{AgCl}, 3 \mathrm{M} \mathrm{NaCl}$ ) for 10 cycles with a scan rate of $0.1 \mathrm{~V} \mathrm{~s}^{-1}$ in a $0.5 \mathrm{M} \mathrm{H}_{2} \mathrm{SO}_{4}$ solution. Then, a constant potential of $-0.2 \mathrm{~V}$ (vs. $\mathrm{Ag} / \mathrm{AgCl}, 3 \mathrm{M} \mathrm{NaCl}$ ) was applied for $100 \mathrm{~s}$ in $0.1 \mathrm{M}$ $\mathrm{CuSO}_{4} / 0.1 \mathrm{M} \mathrm{H}_{2} \mathrm{SO}_{4}$ solution, and the electrodes were thoroughly rinsed and dried. When electrodeposited for $350 \mathrm{~s}$, the mass per unit area of copper on the copper-electrodeposited gold electrode is $0.51 \mathrm{mg} \mathrm{cm}^{-2}$. Nafion was coated by dropping $10 \mu \mathrm{L}$ of $5,10,15$, and $20 \mathrm{wt} \%$ Nafion solution on the electrode surface, and then, the electrodes were dried. When preparing the diluted Nafion solution, a 1-propanol : water $=1: 1$ (volume ratio) solution was used.

\subsection{Electrochemical experiments}

All electrochemical measurements were carried out using an ALS electrochemical analyzer (612Dx, BAS Inc., Tokyo, Japan) with a three-electrode cell system and a silver/silver chloride electrode $(\mathrm{Ag} / \mathrm{AgCl}, 3 \mathrm{M} \mathrm{NaCl})$ as the reference electrode with a potential of $+209 \mathrm{mV}$ vs. SHE, a platinum wire as the counter electrode and a copper-electrodeposited gold electrode with and without Nafion as the working electrode in $0.1 \mathrm{M}$ phosphate buffer ( $\mathrm{pH}$ 7.0). Cyclic voltammetry $(\mathrm{CV})$ was performed by cycling the potential from -0.6 to $0.6 \mathrm{~V}$ at a scan rate of $50 \mathrm{mV} \mathrm{s}^{-1}$. Equipped with a RRDE$3 \mathrm{~A}$ constant rotation system (BAS Inc., Tokyo, Japan), amperometric experiments were conducted at a potential of $-0.1 \mathrm{~V}$ to detect the current response when creatinine was continuously added. The detection sensitivity of creatinine is reported to be highest at $-0.1 \mathrm{~V}$ vs. $\mathrm{Ag} / \mathrm{AgCl}(3 \mathrm{M} \mathrm{NaCl})$ in Ref. 6. Moreover, since it is not easily affected by the interference compound, the applied potential was set to $-0.1 \mathrm{~V}$ vs. $\mathrm{Ag} / \mathrm{AgCl}(3 \mathrm{M} \mathrm{NaCl})$. The working electrode was rotated at $1000 \mathrm{rpm}$ during the measurements. The interference of $1 \mathrm{mM}$ Glu, $4.6 \mu \mathrm{M} \mathrm{DA}, 0.19 \mathrm{mM}$ AA, and $1.9 \mathrm{mM}$ UA was investigated at a potential of $-0.1 \mathrm{~V}$ and a rotation rate of $1000 \mathrm{rpm}$. The concentration of interfering compounds to be examined was calculated using a high value in the standard concentration range, with an average daily urine output of $1.5 \mathrm{~L} .{ }^{7,8}$ The current density without creatinine was set to 0 , and the current density increase due to the addition of creatinine was set to $\Delta j / \mu \mathrm{A} \mathrm{cm}^{-2}$.

\section{Results and Discussion}

\subsection{Electrochemical characterization of the copper-electro- deposited gold electrode}

The cyclic voltammogram obtained for the copper-electrodeposited gold electrode without creatinine shows an anodic peak at $0 \mathrm{~V}$ and a cathodic peak at $-0.3 \mathrm{~V}$. The oxidative peak is attributed to the oxidation of copper, and the reductive peak is attributed to the reduction of copper oxide (Fig. 1). The decreasing reductive peak might result from the decreasing amount of copper oxide because the surface copper oxide is converted into a copper creatinine

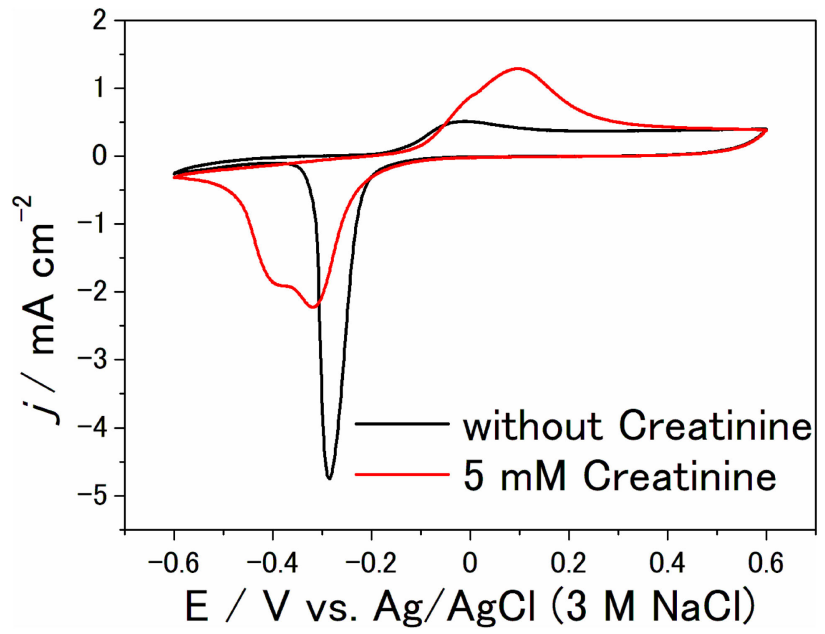

Figure 1. Cyclic voltammograms of a copper-electrodeposited gold electrode in the absence (black) and presence of $5 \mathrm{mM}$ creatinine (red) in $100 \mathrm{mM}$ phosphate buffer $(\mathrm{pH} 7.0)$ at a scan rate of $50 \mathrm{mV} \mathrm{s}^{-1}$.

complex. In addition, the increasing oxidative peak observed in Fig. 1 might result from copper exposure to the electrode surface as the copper ion in copper oxide complexed with creatinine and dissolved in solution. ${ }^{6}$

We performed amperometry at a constant potential of $-0.1 \mathrm{~V}$ vs. $\mathrm{Ag} / \mathrm{AgCl}(3 \mathrm{M} \mathrm{NaCl})$. The current was measured by the successive addition of creatinine to phosphate buffer ( $\mathrm{pH} 7.0)$ every 100 seconds at a rotating rate of $1000 \mathrm{rpm}$ (Fig. S1 of the Supporting Information). The amperometric response increased proportionally to the concentration of creatinine but decreased beyond $1.3 \mathrm{mM}$. The sensor sensitivity from the calibration plots was found to be $133 \pm 1 \mathrm{~mA} \mathrm{~cm}^{-2} \mathrm{M}^{-1}$, and the linear range was from $0.1-1.3 \mathrm{mM}$, with a correlation coefficient of $R^{2}=0.999$. It was shown that amperometric measurements are possible under these conditions. However, normal levels of creatinine in urine have been reported to be $4.0-9.5 \mathrm{mM}$, and the prepared electrode cannot be used for untreated urine. ${ }^{9}$

The effects of typical electrochemically active compounds in urine, such as DA, AA, and UA, were investigated. Since a method for detecting Glu based on a copper electrode in an alkaline solution has been reported, ${ }^{10}$ the effect of Glu was also investigated. The current response was observed when Glu (with a final concentration of $1 \mathrm{mM})$, DA $(4.6 \mu \mathrm{M})$, AA $(0.19 \mathrm{mM})$, and UA $(1.9 \mathrm{mM})$ were sequentially added to a $1 \mathrm{mM}$ creatinine solution at $-0.1 \mathrm{~V}$. There was no response in the case of Glu, DA, and AA. However, with the addition of UA, a $273 \%$ current response to creatinine was obtained (Fig. S2 of the Supporting Information). Since UA reacts to the copper electrode in the same manner as creatinine, the current by UA is observed and UA behaves as an interfering compound.

\subsection{Optimization of the Nafion concentration}

In a previous study, ${ }^{6}$ it was reported that the effect of UA was weakened by modifying the electrode with the $1 \mathrm{wt} \%$ Nafion solution (Nafion on the electrode per unit area is $0.41 \mathrm{mg} \mathrm{cm}^{-2}$ ). Nafion, a polymer with a sulfo group, forms a film with a negative charge on the electrode surface and prevents the current response of $\mathrm{UA}$, which is negatively charged at $\mathrm{pH}$ 7.0. The higher the concentration of the Nafion solution to be applied, the thicker the Nafion film. Therefore, the Nafion film is expected to further prevent the effects of UA. In addition, since the penetration of creatinine could be restricted to some extent, it is expected that even high concentrations of creatinine can be measured. 
Table 1. Interference studies of uric acid in the presence of the Nafion film.

\begin{tabular}{cccc}
\hline $\begin{array}{c}\text { Nafion solution } / \mathrm{wt} \% \\
(\text { mass per unit area/mg cm }\end{array}$ & Creatinine $/ \mu \mathrm{A} \mathrm{cm}^{-2}$ & Uric acid $/ \mu \mathrm{A} \mathrm{cm}^{-2}$ & \multicolumn{2}{c}{$\begin{array}{c}\text { Ratio of the current } \\
\text { densities } \\
\text { (Uric acid/Creatinine)/\% }\end{array}$} \\
\hline $5(6.9)$ & $79.9 \pm 0.9$ & $74.5 \pm 0.1$ & 93.2 \\
$10(13.9)$ & $24.6 \pm 0.8$ & $5.1 \pm 0.1$ & 20.7 \\
$15(20.8)$ & $9.5 \pm 0.5$ & $0.3 \pm 0.1$ & 2.7 \\
$20(27.7)$ & $2.5 \pm 0.4$ & $<0.002$ & $<0.08$ \\
\hline
\end{tabular}

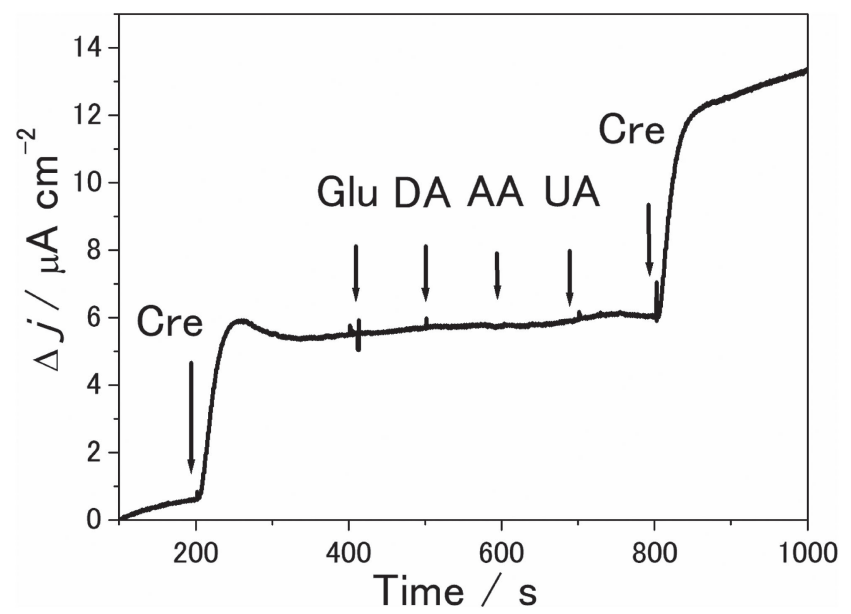

Figure 2. Amperometric response of the $20 \mathrm{wt} \%$ Nafion-modified copper-electrodeposited gold electrode upon the addition of $1 \mathrm{mM}$ creatinine (Cre), $1 \mathrm{mM}$ glucose (Glu), $4.6 \mu \mathrm{M}$ dopamine (DA), $0.19 \mathrm{mM}$ ascorbic acid (AA), and $1.9 \mathrm{mM}$ uric acid (UA) in $100 \mathrm{mM}$ phosphate buffer $(\mathrm{pH} 7.0)$ at $-0.1 \mathrm{~V}$, with a rotating rate of $1000 \mathrm{rpm}$.

Electrodes modified with 5, 10, 15, and $20 \mathrm{wt} \%$ Nafion dispersions were prepared, and the current response was observed when creatinine and interfering compounds were added at $-0.1 \mathrm{~V}$. The current response of UA decreased with increasing concentrations of the Nafion solution, and the effect of UA was largely eliminated by using a $20 \mathrm{wt} \%$ Nafion dispersion (Table 1, Fig. 2). The decrease in response current for creatinine seems to be due to the decrease in the apparent creatinine concentration in the diffusion layer. Modification by the Nafion film reduces the diffusion coefficient of creatinine on the electrode surface.

Creatinine concentration dependence was also observed with the use of $20 \mathrm{wt} \%$ Nafion-modified electrodes. The responses were sluggish but sufficient. (Fig. S3 of the Supporting Information). The sensitivity was $4.03 \pm 0.05 \mathrm{~mA} \mathrm{~cm}^{-2} \mathrm{M}^{-1}$, which was much lower than that in the absence of Nafion $\left(133 \pm 1 \mathrm{~mA} \mathrm{~cm}^{-2} \mathrm{M}^{-1}\right)$, but the linear range was expanded to 1 to $9.1 \mathrm{mM}$. It is considered that the apparent concentration of creatinine decreased due to the effect of the Nafion film, and the amount of copper oxide used in the reaction was reduced, making it possible to measure even high concentrations of creatinine.

\subsection{Optimization of electrodeposition time}

To investigate the effect of the extent of copper electrodeposition on the measurable concentration range, electrodes were prepared with different electrodeposition times, and the creatinine concentration dependence of these electrodes was investigated. The linear range of creatinine concentrations expanded with increasing electrodeposition time. The plots deviated from the straight line

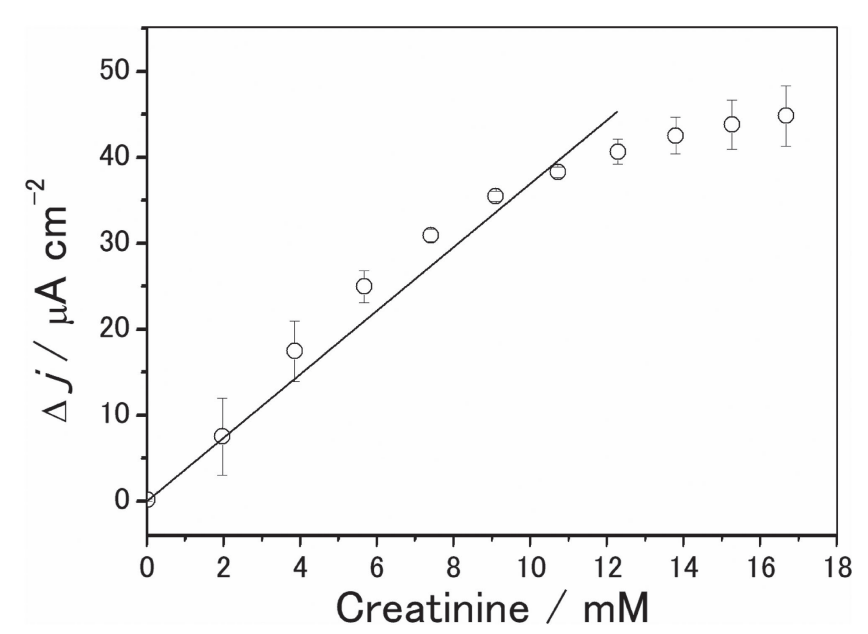

Figure 3. Calibration curves of the $20 \mathrm{wt} \%$ Nafion-modified copper-electrodeposited gold electrode (deposition time: $350 \mathrm{~s}$ ) used for creatinine concentration determination. The line: A line that passes through the origin obtained by the least squares method using data up to $12.3 \mathrm{mM}\left(R^{2}=0.99\right)$.

when electrodes with electrodeposition times of 350 seconds or more were used (Fig. S4A of the Supporting Information). This result suggests that increasing the electrodeposition time increases the amount of copper that can react so that even high concentrations of creatinine can be measured (Fig. S4B of the Supporting Information).

Finally, the creatinine calibration curve was plotted using copper electrodeposition electrodes prepared under optimized conditions (350 second electrodeposition time, $20 \mathrm{wt} \%$ Nafion modification) (Fig. 3). A typical calibration plot from 0 to $12.3 \mathrm{mM}$ with the detection limit of $55.5 \mu \mathrm{M}(\mathrm{S} / \mathrm{N}=3)$, the sensitivity of $3.7 \pm 0.14$ $\mu \mathrm{AmM}^{-1}$, and the response time of $55.0 \pm 1.2 \mathrm{~s}$ is achieved. The results showed linearity $\left(R^{2}=0.99\right)$ up to $12.3 \mathrm{mM}$, which included approximately the standard range of creatinine levels in urine. It was suggested that by using the optimized electrodes, creatinine could be detected even if collected urine was used as a sample without any pretreatment.

\section{Conclusion}

Modifying the copper-electrodeposited gold electrode with a $20 \mathrm{wt} \%$ Nafion solution eliminated the effects of interfering compounds and expanded the measurement concentration range for creatinine measurements. By increasing the electrodeposition time, it was possible to measure even higher concentrations of creatinine. In order to produce a higher performance electrode, the following points need to be considered in the future; (1) detailed observation of the surface condition of the copper-electrodeposited gold electrode, (2) investigation of the influence of the thickness of 
the Nafion film on the permeability of the substance, and (3) the elucidation of the reaction mechanism of the copper electrode to creatinine. The optimized conditions can also be applied to disposable commercially available sensor chips. By using this creatinine measuring electrode together with a sensor that electrochemically measures other urine components, it is possible to instantly correct the component concentration in spot urine. A technique capable of the quantitative evaluation of urine components for use in point-of-care tests has been developed.

\section{Supporting Information}

The Supporting Information is available on the website at DOI: https://doi.org/10.5796/electrochemistry.21-00016.

\section{References}

1. S. B. Heymsfield, C. Arteaga, C. McManus, J. Smith, and S. Moffitt, Am. J. Clin. Nutr., 37, 478 (1983)

2. M. Jaffe, Z. Physiol. Chem., 10, 391 (1886).

3. C. S. Pundir, S. Yadav, and A. Kumar, Trends Anal. Chem., 50, 42 (2013)

4. R. Cánovas, M. Cuartero, and C. A. Crespo, Biosens. Bioelectron., 130, 110 (2019).

5. C. S. Pundir, P. Kumar, and R. Jaiwal, Biosens. Bioelectron., 126, 707 (2019).

6. C. H. Chen and M. S. Lin, Biosens. Bioelectron., 31, 90 (2012).

7. N. W. Shier, T. F. Heinrichs, and W. Hart, J. Food Sci., 47, 334 (1982).

8. C. G. Tsiafoulis, M. I. Prodromidis, and M. I. Karayannis, Biosens. Bioelectron., 20, 620 (2004)

9. A. Ognibene, G. Grandi, M. Lorubbio, S. Rapi, B. Salvadori, A. Terreni, and F. Veroni, Clin. Biochem., 49, 85 (2016).

10. W. Wang, L. Zhang, S. Tong, X. Li, and W. Song, Biosens. Bioelectron., 25, 708 (2009). 